University of Wollongong

Research Online

Faculty of Social Sciences - Papers (Archive) Faculty of Arts, Social Sciences \& Humanities

2009

Writing social determinants into and out of cancer control: An assessment of policy practice

Stacy M. Carter

University of Wollongong, stacyc@uow.edu.au

Claire Hooker

University of Sydney

Heather M. Davey

University of Sydney

Follow this and additional works at: https://ro.uow.edu.au/sspapers

Part of the Education Commons, and the Social and Behavioral Sciences Commons

Research Online is the open access institutional repository for the University of Wollongong. For further information contact the UOW Library: research-pubs@uow.edu.au 


\title{
Writing social determinants into and out of cancer control: An assessment of policy practice
}

\begin{abstract}
A large literature concurs that social determinants of health (SDH) are demonstrable, important, and insufficiently attended to in policy and practice. A resulting priority for research should be to determine how the social determinants of health can best be addressed. In this paper we support the more effective transfer of social determinants research into policy by: (1) describing a qualitative analysis of thirty-two cancer control policy documents from six English-speaking OECD countries and two transnational organizations, demonstrating great variability in the treatment of social determinants in these policies; (2) critiquing these various policy practices in relation to their likely impact on social determinants of health; and (3) advancing a tool that policy writers can use to assess the way in which social determinants of health have been addressed in their work. In the sample of policy documents, the distinction between structural and intermediate determinants, population-based and targeted interventions, and their respective relationships to equity were not always clear. The authors identified four approaches to social determinants (acknowledging SDH, auditing SDH, stating aims regarding SDH and setting out actions on $\mathrm{SDH}$ ), and five ways of writing about the relationship between social determinants and cancer risk. These five discourses implied, respectively: that group membership was intrinsically risky; that not enough was known about $\mathrm{SDH}$; that risk arose from choices made by individuals; that groups were constrained by circumstance; or that structural change was necessary. Socio-cultural factors were generally presented negatively, though New Zealand policies modeled a possible alternative. Based on their empirical work, the authors propose a matrix and a set of questions to guide the development and assessment of health policy.
\end{abstract}

\section{Keywords}

policy, assessment, writing, practice, social, cancer, determinants, control:, into, out

\section{Disciplines}

Education | Social and Behavioral Sciences

\section{Publication Details}

Carter, S. M., Hooker, L. C. \& Davey, H. M. (2009). Writing social determinants into and out of cancer control: An assessment of policy practice. Social Science and Medicine, 68 (8), 1448-1455. 
This is a pre-copyedited, author-produced PDF of an article accepted for publication in Social Science and Medicine following peer review. The definitive publisher-authenticated version [Carter, S., Hooker, C. and Davey, H. (2009) 'Writing Social Determinants Into and Out of Cancer Control: An Assessment of Policy Practice', Social Science and Medicine 68, 1448-55, DOI:

\title{
Writing Social Determinants Into and Out of Cancer Control: An Assessment of Policy Practice
}

\author{
Stacy M. Carter, L. Claire Hooker, Heather M. Davey (2010)
}

\begin{abstract}
A large literature concurs that social determinants of health are demonstrable, important, and insufficiently attended to in policy and practice. A resulting priority for research should be to determine how the social determinants of health can best be addressed. The authors aim to use this paper to support more effective transfer of social determinants research into policy by: (1) describing a qualitative analysis of thirty-two cancer control policy documents from six OECD countries and two transnational organizations, demonstrating great variability in the treatment of social determinants in these policies (2) critiquing these various policy practices in relation to their likely impact on social determinants of health, and (3) advancing a tool that policy writers can use to assess the way in which social determinants of health have been addressed in their work. In the sample of policy documents, the distinction between structural and intermediate determinants, population-based and targeted interventions, and their respective relationships to equity were not always clear. The authors identified four approaches to social determinants (acknowledging SDH, auditing $S D H$, stating aims regarding SDH and setting out actions on $S D H$ ), and five ways of writing about the relationship between social determinants and cancer risk. These five discourses implied, respectively: that group membership was intrinsically risky; that not enough was known about SDH; that risk arose from choices made by individuals; that groups were constrained by circumstance; or that structural change was necessary. Socio-cultural factors were generally presented negatively: New Zealand policies modeled a possible alternative. Based on their empirical work, the authors propose a matrix and a set of questions to guide the development and assessment of health policy.
\end{abstract}

\section{Introduction}

It is widely recognized that persons living in circumstances of greater social and economic disadvantage are at greater risk of ill health: that there are, broadly speaking, Social Determinants of Health (SDH). This observation is both convention and imperative, sufficient to have recently stimulated the World Health Organization (WHO) to establish a Commission on SDH: this Commission has recently produced a final report (World Health Organization, 2007; Commission on Social Determinants of Health 2008). The Commission's goal was not new: reducing inequity has been a stated priority for public health for some thirty years. The WHO's 1978 Declaration of Alma-Ata argued that "the existing gross inequality in the health status of the people ... is politically, socially and economically unacceptable" and the Ottawa 
Charter (World Health Organization, 1986) talked of a health promotion "focuse[d] on achieving equity in health". Despite this, SDH are ignored in many public health interventions (Mechanic, 2000).

\section{What are social determinants of health?}

Social determinants encompass a wide range of interrelated living and working conditions "the social characteristics within which living takes place" (Tarlov, 1996). They are generally divided into structural determinants, such as governance, macroeconomics, policy, culture, social cohesion, class, gender, ethnicity, education, occupation, income, and place, and intermediate determinants, which include material circumstances, psychological makeup, health behavior, biology, and health service provision and access (Mechanic, 2000; Mechanic \& Tanner, 2007; Solar \& Irwin, 2007). Identifying the mechanisms by which these variables influence health is a complex task. Debates exist around issues such as the effect of relative social position versus absolute resources, or negative self-perceptions versus material limitations; whether SES operates through pathways at an individual level and/or causally at a cultural and social level; the degree to which social disadvantage is expressed in individual biology; whether social stratification, unequal risk exposure, unequal vulnerability or unequal consequences of illness are more important; the significance of timing of ill health or risk exposures in the life-course; the temporal and spatial clustering of disadvantage; and the effects of social mobility. Most fundamentally, there is some debate over the direction of the relationship between SES and health (Blane, 2006; Marmot, 2006; Mechanic, 2000; Solar \& Irwin, 2007).

In the face of these debates, what constitutes appropriate intervention? Should policymakers aim to alter structural or intermediate determinants? Should they institute diffuse, population-wide interventions, or interventions targeted to disadvantaged individuals and communities? Let us clarify these important distinctions.

First, the difference between population-wide and targeted interventions. A fundamental principle of public health is that if a risk factor is essentially normally distributed, the majority of the population will be at moderate rather than high risk. The maximum overall change will arise from slight reductions in the risk of the whole population, rather than from identifying and treating the small proportion of high-risk individuals. Population-based strategies explicitly prioritize efficiency - maximum effect for effort. The alternative is a targeted strategy. This involves identifying high-risk individuals or communities (for example, people with poor health literacy, severely deprived neighborhoods) and intervening directly in these individuals or communities. Such intervention can be justified from principles of equity and distributive justice. If it is considered unjust that certain people are substantially less healthy largely because they are socioeconomically deprived, then just policy might aim to transform the shape of the socio-economic distribution of ill health, rather than to move it, intact, towards slightly lower risk.

The distinction between intermediate and structural determinants is also important. Population health interventions usually focus on an intermediate determinant, aiming, for example, to moderately increase the physical activity of the whole population. In theory, but rarely in practice, they could also seek to alter a structural determinant - for example, to moderately increase the educational attainment of the entire population. A populationbased intervention targeting structural determinants can be readily viewed as an intervention in SDH: in fact, the recent WHO Commission final report was notable for recommending almost entirely structural interventions to decrease inequity (Commission on 
Social Determinants of Health, 2008). A population-based intervention in intermediate determinants, however - such as a mass media campaign to encourage more physical activity - seems less likely to impact on inequity. In contrast programs targeted to disadvantaged communities and individuals, whether focused on structural or intermediate determinants, clearly seek to diminish inequities.

Targeted and population-wide approaches are not mutually exclusive or even necessarily in conflict, except when they compete for scarce resources, but they do have different rationales and values at their heart. In this analysis, when looking for SDH in policy we looked for both population-wide intervention in structural determinants and interventions targeted to disadvantaged groups.

\section{The scope and significance of this paper}

Our interest in SDH was engaged while reading cancer control policies and plans from around the world. We are currently undertaking an empirical, qualitative study of lay people's understandings of the risk of getting cancer. For that study, we examined international cancer control policies and plans to assess how policymakers write about cancer risk, with a view to comparing this to the talk of lay participants. Reading through these policy documents, we noticed radical differences in the way in which SDH were discussed and addressed. We became intrigued by the extent of the diversity. There is always some variation in policy practice between countries due to differences in governance, economy, health care systems and cultural approaches to health. Despite this, given that cancer control is strongly interconnected by conferences, the professional literature, e-networks, and leadership from organizations such as the International Union Against Cancer (UICC) and WHO, one would expect relative homogeneity in approaches to $\mathrm{SDH}$. Defying this expectation, the more we read, the more divergent policy practice appeared to be. We thought: given that it is agreed that there is a lot of evidence but not enough policy action on SDH (Commission on Social Determinants of Health, 2008), perhaps it would be useful to systematically examine and write about current policy action in this area.

Consequently, in this paper we aim to support more effective transfer of SDH research into policy by: (1) describing an analysis of cancer control policy documents which demonstrates great variability in the way in which SDH is written into policy, (2) critiquing these various policy practices in relation to their likely impact on SDH, and (3) advancing a tool that policy writers can use to assess the way in which SDH principles have been taken up in their work. Given that creation of policy to address SDH is largely in the development phase, and that the WHO Commission's recent report may stimulate new attention to SDH (Commission on Social Determinants of Health, 2008), this article is particularly timely: it offers guidance to policy makers seeking to extend their work into this important area.

Although we came to these questions as an indirect result of our primary research goals, the cancer control literature is a useful case study within which to analyze approaches to SDH.

As early as 1991 the evidence of the association between cancer and low SES was sufficient for the Director of the US National Cancer Institute to publicly state that "poverty is a carcinogen" (Broder, 1991). More recently, from oncogenesis (Antoni, Lutgendorf, Cole, Dhabhar, Sephton, McDonald et al., 2006) to cancer survival (Woods, Rachet, \& Coleman, 2006), the body of theory and evidence implicating SES in cancer has grown, making social determination a key question for cancer policy-makers. 


\section{Method}

We sought a purposive sample, that is, a sample that would serve the purpose of the study, as is appropriate to qualitative inquiry (Ritchie, Lewis, \& Elam, 2003). Purposive sampling permits flexibility and responsiveness in data collection, and thus maximizes the insight that can be gained from the intensive work of qualitative analysis. Between 24th January 2008 and 31st January 2008, we used the Internet search engine Google to identify policy, strategy or planning documents relevant to cancer control from the major English-speaking member countries of the Organization for Economic Co-operation and Development (OECD): the United Kingdom (UK), the United States of America (USA), Canada, Ireland, New Zealand (NZ) and Australia. We also hand-searched the sites of the WHO and the UICC for documents from those organizations, and searched the databases Medline and ISI Web of Knowledge for references to policies missed in earlier searching. Similar to Anderiesz, Elwood and Hill (2006), we included only documents which: 1 ) addressed cancer as whole; 2) presented entire plans, policies, strategies or positions focused on cancer risk or prevention; and 3) were published in $\mathbf{2 0 0 0}$ or later. We included documents that would assist us to answer our primary research question "how do international cancer control policy documents construct cancer risk?" Documents focused solely on clinical service improvement to people who were unwell were excluded. Searching was restricted to English-language documents because the analysts needed to be fully competent in the language of the data, and the team included only English-speakers. The final sample $(n=32)$ and search strings are listed in Tables 1 and 2 respectively.

\section{Table 1: Search strategies}

\begin{tabular}{|c|c|}
\hline \multirow{2}{*}{\multicolumn{2}{|c|}{$\begin{array}{l}\text { Database/ website Search string/ strategy } \\
\text { Inclusion criteria for all searching: to be included, the document must 1) addresses cancer as whole; } \\
\text { 2) present entire plans, policies, strategies or positions focused on cancer risk or prevention, (that is, } \\
\text { not be focused solely on clinical service improvement to people who were unwell); } 3 \text { ) be published ir } \\
2000 \text { or later. } \\
\text { Searches performed between } 24^{\text {th }} \text { and } 31^{\text {st }} \text { January, } 2008\end{array}$}} \\
\hline & \\
\hline Google & $\begin{array}{l}\text { cancer (risk OR prevention OR control) (policy OR strategy OR plan) } \\
\text { search repeated six times, each time limited to the domain of one } \\
\text { country of interest (the United Kingdom, the United States of } \\
\text { America, Canada, Ireland, New Zealand and Australia respectively) }\end{array}$ \\
\hline WHO website & Searched by hand using the inclusion criteria \\
\hline UICC website & Searched by hand using the inclusion criteria \\
\hline Medline & $\begin{array}{l}\text { (exp neoplasms) AND } \\
\text { (exp primary prevention OR exp health promotion) AND } \\
\text { (public policy OR exp Health Facility Planning/or exp Health } \\
\text { Planning/or exp Community Health Planning/or exp Social } \\
\text { Planning/) } \\
\text { limited to English language reviews }\end{array}$ \\
\hline Web of Knowledge & $\begin{array}{l}\text { Tl=cancer prevent* OR } \\
T I=\text { cancer control } O R \\
\text { Tl=cancer polic* OR } \\
\text { Tl=cancer strateg* } O R \\
T I=\text { cancer plan* } \\
\text { limited to the years } 2000-2007 \text { and to reviews in English. }\end{array}$ \\
\hline
\end{tabular}


Table 2: Final sample of documents

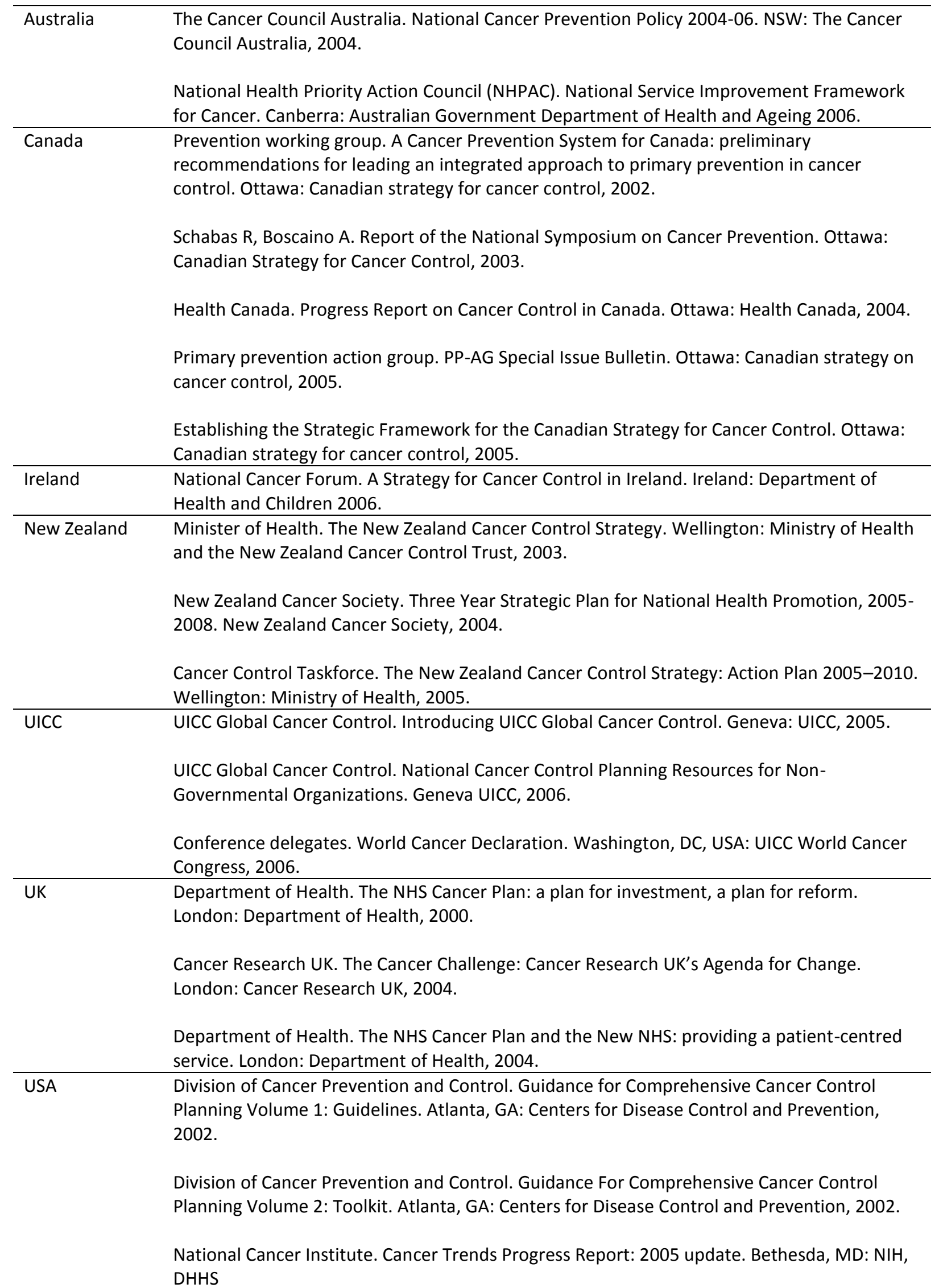


Holly L. Howe XW, Lynn A. G. Ries, Vilma Cokkinides, Faruque Ahmed, Ahmedin Jemal, Barry Miller, Melanie Williams, Elizabeth Ward, Phyllis A. Wingo, Amelie Ramirez, Brenda K. Edwards,. Annual Report to the Nation on the Status of Cancer, 1975-2003, featuring cancer among U.S. Hispanic/Latino populations. Cancer 2006;107(8):1711-1742.

Division of Cancer Prevention and Control. 2006/2007 Division of Cancer Prevention and Control Fact Sheet. Atlanta, GA: Centers for Disease Control and Prevention, 2007.

American Cancer Society. Advocacy and Public Policy: American Cancer Society, 2007.

American Cancer Society. Community Programs and Services: American Cancer Society, 2007.

Centers for Disease Control and Prevention. Preventing and Controlling Cancer, The Nation's Second Leading Cause of Death 2007. Atlanta, GA: U.S. Department of Health and Human Services Centers for Disease Control and Prevention Coordinating Center for Health Promotion, 2007.

Division of Cancer Prevention and Control. National Comprehensive Cancer Control Program Factsheet. Atlanta, GA: Centers for Disease Prevention and Control, 2007.

WHO World Health Organization. National Cancer Control Programmes: policies and managerial guidelines, 2nd edition. Geneva: World Health Organization, 2002.

Fifty-eighth World Health Assembly A58/16. Provisional agenda item 13.12: Cancer Prevention and Control Report by the Secretariat. Geneva: World Health Organization, 2005.

Fifty-eighth World Health Assembly. WHA58.22 Cancer Prevention and Control. Geneva: World Health Organization, 2005.

World Health Organization. Cancer Control, Knowledge into Action. WHO guide for effective programmes: planning. Geneva: World Health Organization, 2006.

World Health Organization. Cancer Prevention: World Health Organization, 2007.

World Health Organization. WHO Cancer Control Strategy: World Health Organization, 2007.

Analysis was inductive and iterative. We began by jointly reading and making informal notes guided by our primary research question. We focused on prevention and early detection because our interest was in prevention and risk. We each observed considerable variation in the way policies and plans used SDH. Each author produced a series of analytic questions based on patterns they observed; these were recorded and discussed, and we arrived at a common list. The questions most relevant to this paper were: [In this policy/plan...]

1) Who is 'at risk'? (Is everyone at risk? Are some groups or individuals especially at risk or not at risk?)

2) Where is cancer or cancer risk located? (In individuals? Societies? Cells? Behavior? Environment? Genes? The availability or competence of screening or treatment facilities? Somewhere else?)

3) To what degree is cancer or cancer risk a product of social structures or determinants? (Reproduce any text discussing SDH; note if not present.)

4) What actions constitute a proper response to cancer or cancer risk? (Protection? Avoidance? Structural interventions? Information giving/knowledge building? Creation of a 'system'? Others?) 
5) Are there solutions that can be applied to 'cancer risk'?

6) Where are the solutions targeted? (At the cancer? The risk? Health behavior? Other? What is the appropriate point at which to measure or intervene?)

7) Are there unproblematic solutions, or are solutions problematic, complex or difficult?

8) What will the outcome be? (Money freed up for other things? Decreased suffering? Healthier populations? Saved lives? The eradication of cancer? Something else?)

9) Whose job is it to do something about cancer or cancer risk? (Who should act?)

10) Who is responsible for reducing cancer risk? (Is anyone to blame?)

We divided the policy papers between authors and worked through them again asking the list of questions that we had developed, regularly comparing and discussing our answers.

Qualitative analysis includes not just comprehending, synthesizing and theorizing, but also recontextualizing in existing work (Morse, 1991). Our analytic work in the documents needed to be recontextualized in the existing literature on SDH. After re-reading key texts (particularly those referenced above) to refine our categories and arguments, we returned to the policy documents a third time, comparing what we had seen in the literature to the approaches to SDH in the policies. Our reporting integrates the work done across these phases of analysis.

\section{Results}

\section{Definitions and levels of intervention}

In the introduction we raised distinctions between population-wide and targeted interventions; and intervention in structural or intermediate determinants. The policy documents were sometimes clear about these distinctions:

This strategy should be population-based first and foremost but also consider the special needs of high-risk nutritionally vulnerable groups (Schabas \& Boscaino, 2003).

....although most cancer occurs in average-risk populations, understand that attention must also be paid to high-risk, underserved populations (Division of Cancer Prevention and Control, 2002).

Others argued explicitly for a population-based approach, implicitly excluding targeted policies:

A comprehensive national cancer programme evaluates the various ways to control disease and implements those that are the most cost-effective and beneficial for the largest part of the population (World Health Organization, 2002).

However these boundaries became blurred in the case of interventions in the physical or social environment, such as instituting shade in public places or creating mass media campaigns. Although it was not uncommon for these to be framed as inherently equitable, this is not necessarily the case. While broad accessibility is a fine principle, it is different from the principle of redistribution underpinning targeted intervention in deprived communities, and few of these interventions could reasonably be considered to radically alter structural determinants of health. Physical or social interventions beg questions about reach, not just in a literal sense (who uses the places where the shade is provided?) but in a 
metaphorical sense (how relevant will a population-wide mass media campaign be to low SES people?). Actions targeted to disadvantaged communities were uncommon: they included, for example, health education designed to be comprehensible for those with low literacy in English, or direction of additional funds to health promotion and community services located in impoverished neighborhoods.

Acknowledging, auditing, stating aims and setting out actions

Every document contained some reference, however tacit, to social determinants. Social determinants appeared in the documents in four ways. Authors acknowledged SDH, audited or recommended auditing SDH, presented their aims regarding SDH, and set out paths of action on SDH. Few documents contained all four, and they did not occur in predictable combinations.

Acknowledging SDH. In some documents, SDH were simply acknowledged. This appeared to be ritualistic, an incantation to be said before the policy or plan got on with the real business of reducing risk:

Prevention is not always a simple matter. People's exposure to risk is generally due to a mix of behavioral, social, economic and cultural factors that are not easy to change (The Cancer Council Australia, 2004).

Cancer is profoundly associated with social and economic status... (World Health Organization, 2002).

Auditing or recommending an audit of SDH. The next means by which policies addressed SDH was either enumerating or advocating the enumeration of incidence, mortality or other outcomes in relation to social, cultural or economic variables:

The HSE should ... monitor inequalities in cancer risks, cancer occurrence, cancer services and cancer outcomes (National Cancer Forum, 2006).

In 1998 in England, 15\% of those in the professional socioeconomic groups smoked compared to $36 \%$ in the unskilled manual group (Department of Health, 2000).

All auditing was not equal. The WHO, for example, in its guide for the creation of cancer control programs (World Health Organization, 2006) established a hierarchy of "core", "expanded", and "desirable" assessments. Assessment of the relationship between SES and cancer was relegated to the least urgent "desirable" category, thus establishing an international benchmark model for cancer control planning in which SDH was only peripheral to the real work of risk reduction, a benchmark that sits in stark contrast to the WHO Commission's recent report, which advocates "ensuring that health inequity is measured" as one of only three overarching recommendations (Commission on Social Determinants of Health, 2008).

Stating aims regarding SDH. Some policies set out aims regarding structural or intermediate $\mathrm{SDH}$. This did not necessarily lead to recommendations for action, but relocated SDH to a more central position amongst the issues at hand:

Guiding principles [include]... focusing on disadvantaged and special population groups having appropriate health services... (National Health Priority Action Council (NHPAC), 2006) 
The overall purposes of the ...strategy [include:] reduce inequalities with respect to cancer (Minister of Health, 2003).

The cancer plan ... has four aims... [including] to tackle the inequalities in health that mean unskilled workers are twice as likely to die from cancer as professionals (Department of Health, 2000).

The most far-reaching aim and the most ambitious auditing occurred in the NHS 2004 cancer plan, which linked the two to create accountability for SDH:

In the new Public Services Agreement (PSA) there is a challenging new target to tackle the social inequalities which exist in relation to death rates from cancer. The target is to achieve a reduction in the inequalities gap of at least $6 \%$ between the fifth of areas with the worst health and deprivation indicators and the population as a whole (Department of Health, 2004).

Setting out actions on SDH. A small number of policies and plans set out actions that would or could be taken to address SDH:

The following set of questions has been developed to assist you to consider how particular inequalities in health have come about, and where the effective intervention points are to tackle them (Cancer Control Taskforce, 2005).

[We will] increase investment in initiatives to improve nutrition and promote healthy weight for low socioeconomic groups [and] encourage increased investment in community based initiatives to improve nutrition and promote healthy weight for Māori (Cancer Control Taskforce, 2005).

The Department of Health will put up to $f 1$ million into funding new local alliances for action on smoking... they will work with the most deprived sections of their communities to make a difference (Department of Health, 2000).

While early statements sometimes acknowledged the importance of general social or economic policies in health outcomes, plans for action were generally targeted to high-risk groups, and focused on intermediate determinants rather than proposing radical intervention in socioeconomic structure. Acknowledgements might suggest, for example, transport or education or employment as sources of inequity, but actions would go no further than attempts to generate specific health behavior change in specific social groups.

Auditing SDH versus taking action on SDH Health financing systems could blur the boundaries between acting and auditing. Because detection occurs relatively later in low SES groups (Woods et al., 2006), a common action was to create programs to encourage disadvantaged populations to be screened more regularly. With universal health care, this was clearly action. In a user-pays system, it was auditing. The US Centers for Disease Control and Prevention (2007), for example, promoted screening programs for indigent, uninsured, and medically underserved people as action on inequity. Although some cancer treatment is available to certain underserved Americans (Centers for Medicare and Medicaid services, 2005), these opportunities are limited. In such a situation, where treatment is unaffordable, screening disadvantaged people could easily become a form of auditing and risk creation, and only primary prevention would constitute real action for risk reduction. 


\section{Locating cancer risk}

Social determination presumes patterning of health risks or outcomes across society. Talking about SDH thus necessitates identifying some groups as being at higher risk than others. Table 3 summarizes five discourses used to relate group membership to cancer risk in the policy documents, each with particular consequences. In the intrinsically risky group discourse, any member of a 'risky' group was automatically and inherently at risk themselves. In the not enough knowledge discourse, action was impossible because of lack of information. This made group members passive, locating solutions (if there were to be any) with health care professionals and researchers. In the risk-taking individuals discourse, the faulty beliefs, knowledge, attitudes, behaviors or choices of individuals had created their own risk. In the constrained by circumstance discourse, the ill health of communities could be explained by the socioeconomic circumstances of their collective lives. The society must change discourse located responsibility outside the group, calling on external actors to change societal structures.

Table 3: Observed discourses relating group membership and cancer risk

\begin{tabular}{|c|c|c|}
\hline Discourse & Function of this discourse & $\begin{array}{l}\text { Language used in this discourse } \\
\text { (For ' } X \text { ' substitute the name of any } \\
\text { socioeconomic group or identity associated with } \\
\text { higher cancer risk) }\end{array}$ \\
\hline $\begin{array}{l}\text { 1. Intrinsically risky } \\
\text { group }\end{array}$ & $\begin{array}{l}\text { Locates cancer risk as intrinsic to } \\
\text { group } \mathrm{X} \text { identity }\end{array}$ & $\begin{array}{l}\text { - X's are at higher risk } \\
\text { - X's are vulnerable } \\
\text { - Being } X \text { is a barrier to prevention }\end{array}$ \\
\hline $\begin{array}{l}\text { 2. Not enough } \\
\text { knowledge }\end{array}$ & $\begin{array}{l}\text { Locates health risk in lack of } \\
\text { knowledge about group } \mathrm{X} \text {; excuses } \\
\text { inaction to reduce risk }\end{array}$ & $\begin{array}{l}\text { - We lack (adequate/systematic) information } \\
\text { about outcomes/interventions in X's }\end{array}$ \\
\hline $\begin{array}{l}\text { 3. Risk-taking } \\
\text { individuals }\end{array}$ & $\begin{array}{l}\text { Locates cancer risk in the } \\
\text { cognitions and actions of } \\
\text { individuals who are members of } \\
\text { group } X\end{array}$ & $\begin{array}{l}\text { - X's have (problematic) knowledge/ attitudes/ } \\
\text { behavior } \\
\text { - X's make unhealthy lifestyle choices } \\
\text { - X's have (problematic/different) health beliefs }\end{array}$ \\
\hline $\begin{array}{l}\text { 4. Constrained by } \\
\text { circumstance }\end{array}$ & $\begin{array}{l}\text { Locates cancer risk in } \\
\text { circumstances which constrain } \\
\text { group } X\end{array}$ & $\begin{array}{l}\text { - X's are exposed to cancer risk } \\
\text { - X's are at high risk because they are } \\
\text { disempowered } \\
\text { - The place in which X's live increases their risk } \\
\text { - X's are at high risk because they do not have } \\
\text { access to services } \\
\text { - X's are at high risk because they are poorly } \\
\text { - educated } \\
\text { - X's are at high risk because they are poor and } \\
\text { deprived } \\
\text { - X's are at high risk because they are of lower } \\
\text { class } \\
\text { - X's are at high risk because they cannot afford } \\
\text { to follow health advice } \\
\text { - X's experience barriers to cancer prevention }\end{array}$ \\
\hline $\begin{array}{l}\text { 5. Society must } \\
\text { change }\end{array}$ & $\begin{array}{l}\text { Locates cancer risk in non- } \\
\text { intervention in the socioeconomic } \\
\text { circumstances of group X }\end{array}$ & $\begin{array}{l}\text { - X's cannot be expected to change unless } \\
\text { underlying socioeconomic problems such as } \\
\text { poverty and underemployment are addressed }\end{array}$ \\
\hline
\end{tabular}


The UK National Health Service (NHS) cancer plans were distinguished by an unusually pervasive use of the constrained by circumstance and society must change discourses, including relatively radical statements such as:

Action to tackle smoking and poor diet will only be effective if the underlying causes are also tackled. Poverty, unemployment and other broader causes of ill health are linked to cancer too, and action across government to tackle health inequalities will in time have an impact on cancer (Department of Health, 2000).

However the risk-taking individuals discourse was more common, and could be used in two ways. First, it was used to silently exclude any consideration of social determination:

Cancer risk factors, such as tobacco smoking, unhealthy diet and physical inactivity, exposure to infections and carcinogens, and longer life expectancy, all contribute to [increased cancer incidence]... and yet we know from research that through appropriate lifestyle choices, up to one-third of all cancers could be prevented (UICC Global Cancer Control, 2006).

Second, it could be used to group persons engaging in undesirable behaviors like smoking under an SES-related label:

Young people who come from low-income families with less education are more likely to smoke. So are those who have less success and involvement in school and fewer skills to resist the pervasive pressures to use tobacco (National Cancer Institute, 2005).

The five discourses (intrinsically risky group, not enough knowledge, risk-taking individuals, constrained by circumstance, society must change) interacted with the four approaches to SDH (acknowledging, auditing, stating aims and setting out actions). Most commonly, a document would use society must change or constrained by circumstance discourses when acknowledging SDH and/or stating aims, but then would set out actions that were more consistent with the risk-taking individuals discourse. Strong establishing motherhood statements about the need for inter-sectoral efforts to improve employment and education, for example, might be followed by actions designed to make the whole population give up smoking and eat differently.

\section{Constructing cultural identity}

Social determinants of health are not merely economic: they are also social and cultural, and socioeconomic status and culture are linked. Subcultures are created by their members, provide their members with belonging, meaning and identity, and constrain their members; subcultural identity contains and transcends advantage or disadvantage (Petersen \& Lupton, 1996). In these documents, cultures were "determinants" only when they created a hazard. A person who was Aboriginal or a manual laborer, for example, was deemed to be at increased cancer risk and thus "appeared" in policy. The converse was also true: any subculture not "at risk" did not appear in policy, despite being the implicit audience for many of the population-based interventions proposed. Thus social and cultural distinctions were written into cancer policy in a one-dimensional way: they existed only as negatives, and policies rarely acknowledged the richness, complexity and overlapping nature of cultural identities. 
Policy discourse about Indigenous Australians illustrates this principle. Aboriginal and Torres Strait Islander Australians appeared frequently in these policies, while non-Indigenous Australians were invisible unless they had an additional 'problematic' identity. When Indigenous Australians appeared, the intrinsically risky group and not enough knowledge discourses dominated, with the latter often used rhetorically to avoid setting out a clear plan for action, and there was little sense of Indigenous Australian cultures as rich or valuable:

Some groups have been identified as requiring particular attention. These include Australian Aboriginal and Torres Strait Islander people... [who] have high smoking prevalence... are particularly at risk... are at higher risk of obesity... [have] a higher rate of cervical cancer... liver cancer... cancer death rates are much higher than in the general population... misuse of alcohol is of particular concern, even though teetotalism rates are highest in this group... An important gap has been identified... the need for national data to inform action on cancer in Aboriginal and Torres Strait Islander peoples... most of the programs that have been implemented have not been evaluated... (The Cancer Council Australia, 2004)

Policy documents from New Zealand (NZ) suggested an alternative (Cancer Control Taskforce, 2005; Minister of Health, 2003; New Zealand Cancer Society, 2004). In NZ documents, both Māori and non-Māori (Pākehā) appeared. Disparities between Māori and non-Māori health outcomes were highlighted, but these documents also set out aims, recommended actions, and most fundamentally, used the cultural values and understandings of Māori and Pacific Islander peoples to talk about cancer risk:

Cancer Society health promotion activities will be consistent with and reflect a commitment to the Treaty of Waitangi. This approach recognizes that Māori have identified the Treaty as a preferred framework within which their health needs should be addressed ... This section outlines what it means in practical terms for the Society to apply the Treaty in its health promotion activities (New Zealand Cancer Society, 2004).

This strategy has been designed to be consistent with Māori needs and expectations, and to enable the dual goals of Māori development and improving Māori health. This requires acknowledging the Treaty of Waitangi, action to reduce inequalities [and] the explicit use of Māori concepts of hauora [that is, health as the integration of physical, mental, emotional, social and spiritual well-being], whānau [extended family], and whānau ora [that is, supporting Māori extended families to achieve maximum health and wellbeing] (Minister of Health, 2003).

Australian and NZ policies were fundamentally, epistemologically different. Australian policies constructed Indigenous peoples as inherently risky and frequently used 'knowledge gaps' to excuse inaction. The NZ policies set out actions guided by Māori ways of being and knowing, explicitly positing that these had value in NZ society. It should be noted that the NZ policy environment differs from the Australian environment (in particular, the Treaty of Waitangi provides an important framework, and practical policy tools have been established to encourage action on inequities). Māori peoples are also more unified in political, language, cultural and policy terms than Indigenous Australians. We are not naively assuming that a difference in policy transparently corresponds to a difference in implemented action. However these contrasting case studies do illustrate our key points in this section: that cancer policy can construct the identity of subcultures within communities, 
that at present many such policies talk about subcultures only when they are deemed hazardous while allowing 'mainstream' cultures to remain invisible, and that models for alternative policy practices exist.

\section{Discussion}

If $\mathrm{SDH}$ research is to generate positive impacts, it must be written into policy in an effective way. Our study indicated that this is not currently occurring. Policies acknowledge SDH, or on occasion enumerate it, and treat social inequality as intrinsic to particular groups, as arising from individual choices, or as unable to be addressed because of knowledge gaps. These documents fore-grounded SDH as significant for cancer control in rhetoric, but their recommendations for prevention centered almost entirely on generating individual behavior change, with minimal attention to the social and environmental context needed to achieve this. Social inequalities in health outcomes seem unlikely to change as long as SDH research is incorporated into policy in such a limited way.

This study cannot tell us why current cancer policy looks the way it does. As qualitative researchers, we are keenly aware of the detailed empirical research required to understand any process as complex as policy-making. We can, however, hypothesize. The effects of neoliberal governmental frameworks, the political imperatives surrounding individual diseases but not structural inequities, a lack of championing of SDH within policy processes, and the established everyday rituals of organizations could all conspire against a concerted effort to address SDH in cancer policy. Determining which of these are factors and the process by which they operate are questions for future research. Related to this, we note that this work focuses on a relatively homogenous population of policy documents, and that further research could examine the degree to which our findings apply in other political contexts, for other diseases, in other languages, or even for a more generalized and coordinated effort in chronic disease prevention. We note that we included policies from transnational NGOs which represent member-states and organizations working in non-English languages, suggesting the possibility of relevance beyond English-language policy environments.

Given that SDH policy is in development globally, this paper provides a timely and important opportunity to suggest how SDH might be written into cancer policy. As a starting point, we suggest a need for a clearer distinction between structural and intermediate determinants, and between population-level versus targeted interventions. There are arguments for and against each of these, but they should not be elided in policymaking. In addition, as a guide for developing and assessing health policy, we propose the matrix in Table 4, based directly on our empirical findings. To use the matrix, a health policymaker would first examine a draft policy and determine how it approaches SDH (acknowledging, auditing, stating aims and setting out actions) and how SDH are written about (this is an intrinsically risky group, there is not enough knowledge, these individuals are taking risks, this group is constrained by circumstance or society must change). They would then record all the instances in which the approaches to SDH and ways of writing about SDH overlap. This would help ensure that the policy does not merely acknowledge SDH, but also aims and acts in order to actually achieve SDH goals, and that SDH is framed in a productive and consistent manner. Table 4 presents an example of the kind of text that might belong in each cell. (Note that this is for the purposes of conceptual illustration only. If the matrix was used to analyze a typical policy, few cells would contain text, and the "auditing", "aims" and "actions" columns would probably be empty.) 
Table 4: A tool for writing SDH into health policy

\begin{tabular}{|c|c|c|c|c|c|}
\hline & When we are... & $\begin{array}{l}\text { Acknowledging } \\
\text { SDH }\end{array}$ & $\begin{array}{l}\text { Auditing } \\
\text { SDH }\end{array}$ & $\begin{array}{l}\text { Stating aims } \\
\text { regarding SDH }\end{array}$ & $\begin{array}{c}\text { Setting out } \\
\text { actions on SDH }\end{array}$ \\
\hline \multirow{5}{*}{ 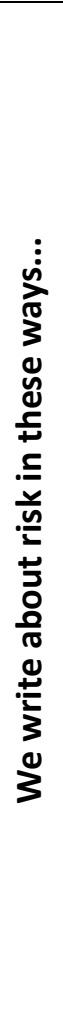 } & Intrinsically risky group & $\begin{array}{l}\text { People of Indigenous } \\
\text { descent are of particular } \\
\text { concern. }\end{array}$ & $\begin{array}{l}\text { Health planners should } \\
\text { identify which population } \\
\text { groups have poorer health } \\
\text { outcomes. }\end{array}$ & $\begin{array}{l}\text { We aim to reduce cancer risk } \\
\text { in Indigenous communities. }\end{array}$ & 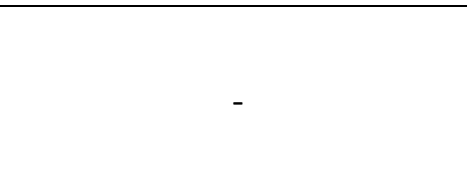 \\
\hline & Not enough knowledge & $\begin{array}{c}\text { The relationship between } \\
\text { SES and cancer risk is } \\
\text { unclear. }\end{array}$ & $\begin{array}{l}\text { We will include indicators of } \\
\text { SES in cancer registry data } \\
\text { collections. }\end{array}$ & $\begin{array}{l}\text { We aim to develop a better } \\
\text { understanding of the impact } \\
\text { of social class. }\end{array}$ & $\begin{array}{l}\text { We will synthesize existing } \\
\text { knowledge on the } \\
\text { relationship between social } \\
\text { determinants and cancer. }\end{array}$ \\
\hline & Risk-taking individuals & $\begin{array}{l}\text { Young people from low- } \\
\text { income families engage in } \\
\text { more unhealthy behaviors. }\end{array}$ & $\begin{array}{c}\text { Figure } 4 \text { illustrates the } \\
\text { distribution of high-risk } \\
\text { behaviors by level of income. }\end{array}$ & $\begin{array}{c}\text { We aim to reduce } \\
\text { population smoking rates to } \\
\text { below } 18 \% \text { by } 2012 \text {. }\end{array}$ & $\begin{array}{c}\text { We will roll out new mass } \\
\text { media quit smoking } \\
\text { campaigns nationally. }\end{array}$ \\
\hline & $\begin{array}{l}\text { Constrained by } \\
\text { circumstance }\end{array}$ & $\begin{array}{l}\text { Poverty and a low level of } \\
\text { education are barriers to } \\
\text { accessing prevention. }\end{array}$ & $\begin{array}{c}\text { As Table } 3 \text { illustrates, people } \\
\text { earning lower incomes have } \\
\text { significantly worse } 5 \text {-year } \\
\text { cancer survival. }\end{array}$ & $\begin{array}{c}\text { We aim to tackle inequalities } \\
\text { in health that mean unskilled } \\
\text { workers are twice as likely to } \\
\text { die from cancer as } \\
\text { professionals. }\end{array}$ & $\begin{array}{l}\text { We will target interventions } \\
\text { to ensure better tailored and } \\
\text { more affordable access for } \\
\text { impoverished communities. }\end{array}$ \\
\hline & Society must change & $\begin{array}{l}\text { Action to tackle smoking and } \\
\text { poor diet will only be } \\
\text { effective if the underlying } \\
\text { structural problems are also } \\
\text { tackled. }\end{array}$ & $\begin{array}{l}\text { We must supplement the } \\
\text { existing research focused on } \\
\text { individual behavior with } \\
\text { investigation of } \\
\text { organizational and } \\
\text { environmental change. }\end{array}$ & $\begin{array}{l}\text { We aim to improve } \\
\text { population health over time } \\
\text { by increasing participation in } \\
\text { education and employment. }\end{array}$ & $\begin{array}{c}\text { We will institute programs to } \\
\text { decrease poverty, } \\
\text { unemployment and other } \\
\text { broader causes of ill health. }\end{array}$ \\
\hline
\end{tabular}


When the table is complete, we suggest using the following questions to examine the matrix:

1) Has this policy audited SDH, stated aims regarding SDH and set out actions regarding SDH?

2) Has this policy acknowledged SDH but not set out any aims or actions?

a) If so, what purpose does the acknowledgement serve?

b) Why has the policy not also stated aims or set out actions?

c) Would it be more honest to remove the acknowledgement?

3) Where has the intrinsically risky group discourse been used?

a) What are the effects of this?

b) Can it be removed?

4) Have we used the not enough knowledge discourse to justify inaction?

a) If so, is this truly justified?

5) Is there a mismatch between the discourses used when acknowledging and stating aims, and the discourses used when setting out actions or auditing SDH? For example, does the policy acknowledge that people are constrained by circumstance, but then set out actions designed only to alter behavior, thus individualizing risk?

a) If so, how can this be rectified?

6) Are we intervening in structural or intermediate determinants? Are we using a populationwide or a high-risk targeted strategy?

a) Given this, are we making appropriate equity claims?

7) If we are targeting particular community groups, have we made efforts to include their epistemologies in our policies and plans?

In proposing this matrix and a system for its use, we are making judgments about what constitutes valid employment of SDH in cancer control policy. We believe that current practices have the potential to stigmatize "at risk" groups, creating an imperative for surveillance which further heightens the perceived "riskiness" of the group, but neglects underlying inequities (Petersen \& Lupton, 1996). Risk is, as Mary Douglas argues, inherently political, ideological and to do with values: it is a forensic resource that enables blame to be read in a culture (Douglas, 1992). Labeling an individual or community "at risk" can construct them as deserving or undeserving, sinners or victims, unlucky or responsible for their own fate as a result of willful wrongdoing (Ferguson, 2007; Mechanic $\&$ Tanner, 2007). Addressing cancer risk only through behavioral interventions locates responsibility with individuals. Merely acknowledging the social determinants of cancer in policy without stating aims or setting out actions potentially stigmatizes whilst abrogating responsibility. The framing of risk in cancer control policy can thus be seen as an instrument for the attribution of responsibility as much as it is a tool for health improvement. The example of NZ policy documents shows that policy makers can avoid simplistic negative representations by taking up the epistemology of the groups deemed to be "at risk", and rare policies (especially those from the UK) show that it is possible to acknowledge, audit, aim and set out actions on the social determinants of cancer.

This work complements that of the WHO's Commission on Social Determinants of Health (Solar \& Irwin, 2007; Commission on Social Determinants of Health, 2008). The Commission's final report emphasized structural change, advocating cross-sectoral effort to improve daily living conditions, tackle the inequitable distribution of money, power and resources, and include SDH in routine surveillance (Commission on Social Determinants of Health, 2008). This analysis suggests that, at 
least in cancer policy, the Commission's extensive report may become nothing more than a routinized footnote for opening rhetoric, a preliminary acknowledgement before policy-makers get down to the "real business" of stimulating diffuse health behavior change across populations. By providing a detailed examination of the published work of policymakers, we hope that we have challenged them to work differently. If, as the WHO Commission advocates, we are to "close the health gap in a generation" (Commission on Social Determinants of Health, 2008), it will be necessary to communicate differently about social determinants and sub-cultural groups, and to begin auditing $\mathrm{SDH}$, constructing policy aims and planning policy actions to effectively address longstanding local and global health inequities.

\section{References}

Anderiesz, C., Elwood, M., \& Hill, D. (2006). Cancer control policy in Australia. Australia and New Zealand Health Policy, 3(1), 12.

Antoni, M. H., Lutgendorf, S. K., Cole, S. W., Dhabhar, F. S., Sephton, S. E., McDonald, P. G., et al. (2006). The influence of bio-behavioural factors on tumour biology: pathways and mechanisms. Nature Reviews, Cancer. 6(3), 240-248.

Blane, D. (2006). The life course, the social gradient and health. In M. Marmot \& R. Wilkinson (Eds.), Social determinants of health (pp. 54-77). Oxford: Oxford University Press.

Broder, S. (1991). Progress and challenges in the National Cancer Program. In J. Burgge, T. Curran, E. Harlow \& F. McCormick (Eds.), Origins of Human Cancer. New York: Cold Spring Harbor Laboratory Press

Cancer Control Taskforce. (2005). The New Zealand Cancer Control Strategy: Action Plan 2005-2010. Wellington: Ministry of Health.

Commission on Social Determinants of Health (2008). Closing the gap in a generation: health equity through action on the social determinants of health. Final Report of the Commission on Social Determinants of Health. Geneva: World Health Organization.

Centers for Disease Control and Prevention. (2007). Preventing and Controlling Cancer, The Nation's Second Leading Cause of Death 2007. Atlanta, GA: U.S. Department of Health and Human Services Centers for Disease Control and Prevention Coordinating Center for Health Promotion.

Centers for Medicare and Medicaid Services. (2005). Breast and Cervical Cancer: Prevention and Treatment. US Department of Health and Human Services.

Department of Health. (2000). The NHS Cancer Plan: a plan for investment, a plan for reform. London: Department of Health, .

Department of Health. (2004). The NHS cancer plan and the new NHS: providing a patient-centred service. London: Department of Health.

Division of Cancer Prevention and Control. (2002). Guidance for Comprehensive Cancer Control Planning Volume 1: Guidelines. Atlanta, GA: Centers for Disease Control and Prevention.

Douglas, M. (1992). Risk and blame: essays in cultural theory. London: Routledge.

Ferguson, C. (2007). Barriers to serving the vulnerable: thoughts of a former public official. Health Affairs, 26(5), 1358-1365.

Marmot, M. (2006). Introduction. In M. Marmot \& R. Wilkinson (Eds.), Social determinants of health (pp. 1-5). Oxford: Oxford University Press. 
Mechanic, D. (2000). Rediscovering the social determinants of health. Health Affairs, 19(3), 269-276.

Mechanic, D., \& Tanner, J. (2007). Vulnerable people, groups, and populations: societal view. Health Affairs, 26(5), 1220-1231.

Minister of Health. (2003). The New Zealand Cancer Control Strategy. Wellington: Ministry of Health and the New Zealand Cancer Control Trust.

Morse, J. (1991). "Emerging from the data": the cognitive process of analysis in qualitative inquiry. In J. Morse (Ed.), Critical issues in qualitative methods (pp. 23-43). Thousand Oaks, CA: Sage Publications.

National Cancer Forum. (2006). A strategy for cancer control in Ireland. Ireland: Department of Health and Children.

National Cancer Institute. (2005). Cancer trends progress report: 2005 update. Bethesda, MD: NIH, DHHS

National Health Priority Action Council (NHPAC). (2006). National Service Improvement Framework for Cancer. Canberra: Australian Government Department of Health and Ageing

New Zealand Cancer Society. (2004). Three year strategic plan for national health promotion, 20052008. New Zealand Cancer Society.

Petersen, A., \& Lupton, D. (1996). The new public health: health and self in the age of risk. St Leonards NSW: Allen \& Unwin.

Ritchie, J., Lewis, J., \& Elam, G. (2003). Designing and selecting samples. In J. Ritchie \& J. Lewis (Eds.), Qualitative research practice (pp. 77-108). Thousand Oaks, CA: SAGE Publications Ltd.

Schabas, R., \& Boscaino, A. (2003). Report of the national symposium on cancer prevention. Ottawa: Canadian Strategy for Cancer Control.

Solar, O., \& Irwin, A. (2007). A conceptual framework for action on the social determinants of health: World Health Organization Commission on Social Determinants of Health Discussion Paper.

Tarlov, A. (1996). Social determinants of health: the sociobiological translation. In D. Blane, E. Brunner \& R. Wilkinson (Eds.), Health and social organization (pp. 71-93). London: Routledge.

The Cancer Council Australia. (2004). National Cancer Prevention Policy 2004-06. Camperdown, NSW: The Cancer Council Australia.

UICC Global Cancer Control. (2006). National Cancer Control Planning Resources for NonGovernmental Organizations. Geneva UICC.

Woods, L. M., Rachet, B., \& Coleman, M. P. (2006). Origins of socio-economic inequalities in cancer survival: a review. Annals of Oncology, 17(1), 5-19.

World Health Organization. (1978). Declaration of Alma-Ata. Geneva: World Health Organization.

World Health Organization. (1986). Ottawa Charter for Health Promotion. Geneva: World Health Organization.

World Health Organization. (2002). National cancer control programmes: policies and managerial guidelines, 2nd edition. Geneva: World Health Organization.

World Health Organization. (2006). Cancer control, knowledge into action, WHO guide for effective programmes: planning. Geneva: World Health Organization.

World Health Organization. (2007). Interim Statement of the Commission on Social Determinants of Health 